\title{
Association of PNPLA3 rs738409 G/C gene polymorphism with nonalcoholic fatty liver disease in children: a meta-analysis
}

Shan Tang ${ }^{\dagger}$, Jing Zhang ${ }^{\dagger}$, Ting Ting Mei, Hai Qing Guo, Xin Huan Wei, Wen Yan Zhang, Ya Li Liu, Shan Liang, Zuo Peng Fan, Li Xia Ma, Wei Lin, Yi Rong Liu, Li Xia Qiu and Hai Bin Yu* (D)

\begin{abstract}
Background: Nonalcoholic fatty liver disease (NAFLD) is one of the most common causes of chronic liver disease worldwide. Current studies have shown that PNPLA3 (Patatin-like phospholipase domain containing 3) rs738409 G/ $\mathrm{C}$ gene polymorphism is associated with adult nonalcoholic fatty liver disease [1,2].But there is no consensus on the relationship between PNPLA3 rs738409 G/C gene polymorphism and children NAFLD due to differences in population samples. To this end, a meta-analysis of published research is conducted to comprehensively assess the relationship between PNPLA3 gene polymorphism and NAFLD in children.

Methods: We searched MEDLINE, PubMed, EMBASE, and CENTRAL databases from inception to May 2019. Casecontrol studies assessing the relationship between PNPLA3 rs738409 G/C gene polymorphism with non-alcoholic fatty liver disease in children were selected according to inclusion and exclusion criteria. Random effects model was used to quantify the association between the PNPLA3 rs738409 G/C gene polymorphism and the susceptibility of children's NAFLD. Fixed effects model was used to quantify the relationship between the PNPLA3 rs738409 G/C gene polymorphism and the severity of NAFLD in children. The Stata 12.0 software was employed for data analysis.

Results: A total of nine case-control studies were included in this meta-analysis containing data of 1173 children with NAFLD and 1792 healthy controls. Five studies compared NAFLD children and non-NAFLD healthy populations. Statistical analysis showed that PNPLA3 gene polymorphism was significantly associated with children's NAFLD in the allele contrast, dominant, recessive and over dominant models ( $G$ vs $C, O R=3.343,95 \% \mathrm{Cl}=1.524-7.334 ; \mathrm{GG}+\mathrm{GC}$ vs $\mathrm{CC}, \mathrm{OR}=3.157,95 \% \mathrm{Cl}=1.446-6.892 ; \mathrm{GG}$ vs GC $+\mathrm{CC}, \mathrm{OR}=5.692,95 \% \mathrm{Cl}=1.941-16.689 ; \mathrm{GG}+\mathrm{CC}$ vs GC,OR=2.756, 95\% $\mathrm{Cl}=1.729-4.392)$. Four case-control studies compared Children with nonalcoholic fatty liver (NAFL) and children with nonalcoholic steatohepatitis (NASH). The results showed that the PNPLA3 gene polymorphism was also significantly associated with the severity of NAFLD in children in recessive gene model (GG vs GC + CC,OR $=14.43,95 \% \mathrm{Cl}=5.985-$ 34.997); The Egger's test revealed no significant publication bias.
\end{abstract}

Conclusions: Meta-analysis showed that PNPLA3 gene polymorphism was significantly associated with susceptibility and severity of NAFLD in children.

Keywords: PNPLA3, Meta-analysis, Polymorphism

\footnotetext{
* Correspondence: xiaobenyu2002@163.com

'Shan Tang and Jing Zhang contributed equally to this work. Department of Hepatitis C and Drug-Induced Liver Injury, Beijing YouAn Hospital, Capital Medical University, Beijing 100069, China
}

(c) The Author(s). 2020 Open Access This article is licensed under a Creative Commons Attribution 4.0 International License, which permits use, sharing, adaptation, distribution and reproduction in any medium or format, as long as you give appropriate credit to the original author(s) and the source, provide a link to the Creative Commons licence, and indicate if changes were made. The images or other third party material in this article are included in the article's Creative Commons licence, unless indicated otherwise in a credit line to the material. If material is not included in the article's Creative Commons licence and your intended use is not permitted by statutory regulation or exceeds the permitted use, you will need to obtain permission directly from the copyright holder. To view a copy of this licence, visit http://creativecommons.org/licenses/by/4.0/ The Creative Commons Public Domain Dedication waiver (http://creativecommons.org/publicdomain/zero/1.0/) applies to the data made available in this article, unless otherwise stated in a credit line to the data. 


\section{Background}

Nonalcoholic fatty liver disease (NAFLD) is one of the most common causes of chronic liver disease worldwide. The prevalence of NAFLD in children has reached about $10 \%$, and in obese children has reached $40-70 \%$ [3].NAFLD includes nonalcoholic fatty liver (NAFL), nonalcoholic steatohepatitis (NASH),fatty liver fibrosis and cirrhosis. NAFL usually has no obvious clinical symptoms, but hepatocyte injury can lead to the occurrence of $\mathrm{NASH}$, liver fibrosis and cirrhosis in $3-5 \%$ of patients [4]. Therefore, assessing the genetic factors of children's NAFLD to early diagnose the disease, early judge the severity of the disease is the key to improve prognosis. Current studies have shown that PNPLA3 (Patatin-like phospholipase domain containing 3) rs738409 G/C gene polymorphism is associated with adult nonalcoholic fatty liver disease $[1,2]$.But there is no consensus on the relationship between PNPLA3 rs738409 G/C gene polymorphism and children NAFLD due to differences in population samples, detection methods and diagnostic criteria. To this end, a meta-analysis of published research is conducted to comprehensively assess the relationship between PNPLA3 gene polymorphism and NAFLD in children.

\section{Methods}

The authors performed the meta-analysis according to the Preferred Reporting Items for Systematic Reviews and Meta-Analyses (PRISMA). The meta analysis was registered in PROSPERO. (PROSPERO CRD42019134056).

\section{Study strategy}

MEDLINE、PubMed、EMBASE and CENTRAL were used for the potential studies searching. (NAFLD OR Non alcoholic Fatty Liver Disease OR Nonalcoholic Fatty Liver Disease OR Nonalcoholic Fatty Liver OR Nonalcoholic Fatty Livers OR Nonalcoholic Steatohepatitis OR Nonalcoholic Steatohepatitides) AND (PNPLA3 OR patatin-like phospholipase domain-containing 3) AND ("Child"OR "Adolescent" OR child OR children OR Adolescent* OR student*) were used as the key words

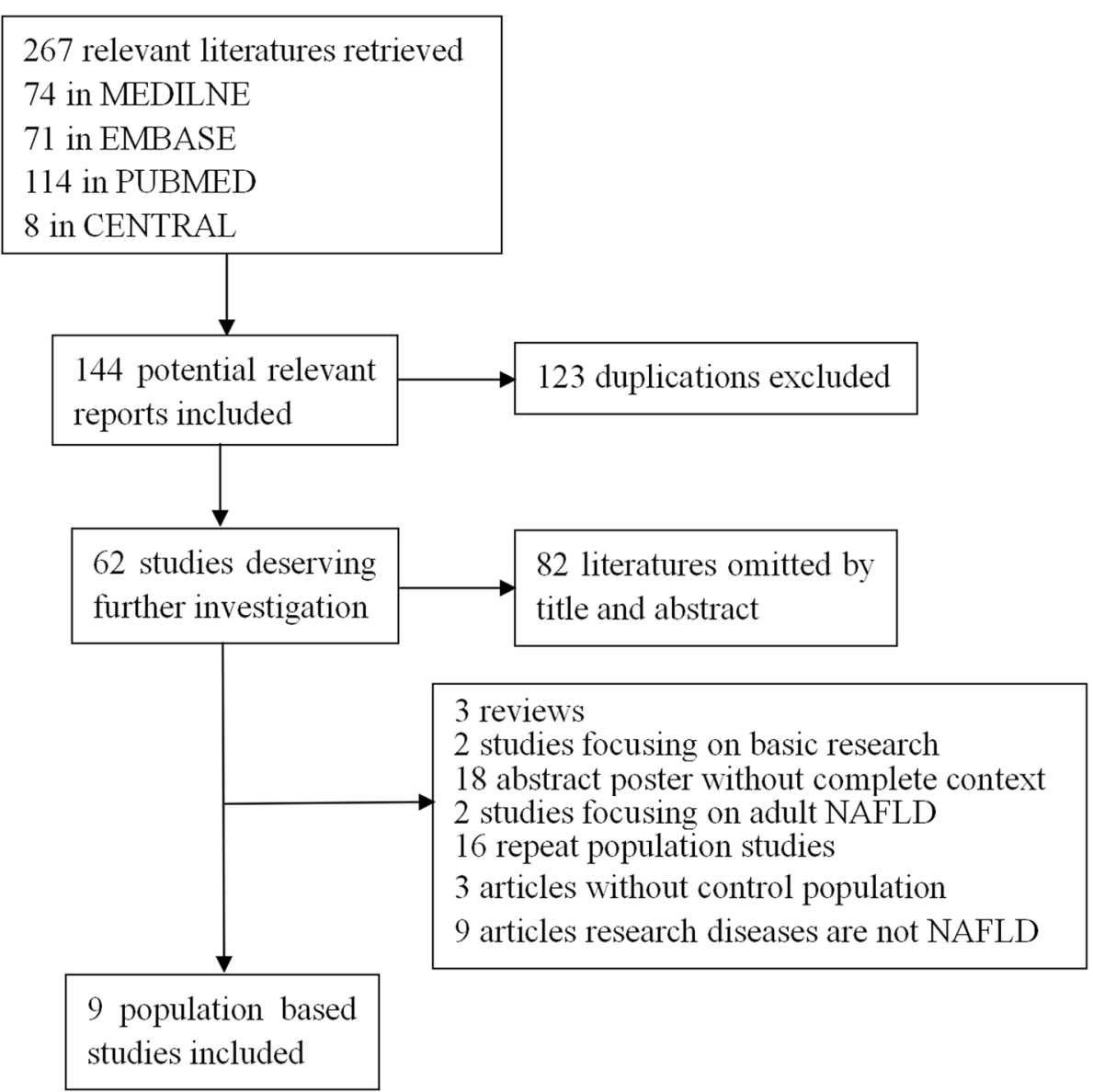

Fig. 1 Flow diagram for study selection 
or Mesh terms for searching. The final search was conducted up to May 2019.

\section{Selection of studies}

Any study included in current meta-analysis must satisfy the following criteria:1) the study cohorts include PNPL A3 rs738409 G/C gene polymorphism in children with NAFLD and non-NAFLD individuals;2) case-control studies;3) if duplicate research reports was retrieved, the most comprehensive one was selected to avoid repeated statistics. 4) the study contained sufficient data of genotype frequency.Articles were excluded based on the following criteria: 1) studies without controls groups;2) the enrolled case groups are not children patients;3) studies without specific distribution of genotype;4) studies reported animal models.

\section{Data extraction and analysis}

Two reviewers independently assessed and reviewed all identified studies in terms of inclusion and exclusion criteria. Conflicts were reached to agreement via the discussion with the third authors.And they extracted data from the original publications: author, year of publication, country of origin, design of the trial, total numbers of patients in the case and control groups, sex ratio, body mass index (BMI), the numbers of cases and controls with the $C / C, C / G$, and $G / G$ genotypes, whether genotype distribution was consistent with the HardyWeinberg equilibrium (HWE). This meta-analysis preformed the data analyzing by using Stata version 12.0.The association of the $\mathrm{G} / \mathrm{C}$ polymorphism in the PNPLA3 gene with NAFLD in children susceptibility was evaluated in the allelic, dominant, recessive, and super-dominant models. The association of the G/C polymorphism in the PNPLA3 gene with NASH in children susceptibility was evaluated in the recessive model. The results were evaluated using the OR value and the corresponding 95\% confidence interval (CI). The evaluation of heterogeneity of studies was using the $Q$ test and was quantified using $I^{2}$. The fixed-effects model was used when $I^{2}<50 \%$. In contrast, the random-effects model was applied when $I^{2}>50 \%$. The suitability test was used to check whether the gene distribution of the control group consistent with the Hardy-Weinberg equilibrium, and the $\mathrm{P}_{\mathrm{H}-\mathrm{W}}>0.05$ was regarded as consistent with the HWE.The sensitivity analysis was performed by assessing the change of combined ORs values after elimination of each individual study.The publication bias was evaluated using the Egger linear regression method and funnel chart.

Table 1 Characteristics of the studies included in the meta-analysis

\begin{tabular}{|c|c|c|c|c|c|c|c|c|c|c|c|c|c|c|}
\hline \multirow{2}{*}{$\begin{array}{l}\text { First author, } \\
\text { year, study }\end{array}$} & \multirow{2}{*}{$\begin{array}{l}\text { Cohort } \\
\text { characteristics }\end{array}$} & \multirow[t]{2}{*}{ Country } & \multirow{2}{*}{$\begin{array}{l}\text { Gender } \\
\text { (men/women) }\end{array}$} & \multirow{2}{*}{$\begin{array}{l}\text { BMI } \\
(\text { mean } \pm S D)\end{array}$} & \multirow{2}{*}{$\begin{array}{l}\text { Study } \\
\text { design }\end{array}$} & \multirow[t]{2}{*}{ Genotyping } & \multirow{2}{*}{$\begin{array}{l}\text { Sample } \\
\text { size }\end{array}$} & \multicolumn{3}{|c|}{ genotype } & \multicolumn{2}{|c|}{ allele } & \multirow[t]{2}{*}{ HWE } & \multirow[t]{2}{*}{$\mathrm{P}_{\mathrm{H}-\mathrm{W}}$} \\
\hline & & & & & & & & CC & GC & $\mathrm{GG}$ & $\mathrm{G}$ & C & & \\
\hline \multirow[t]{2}{*}{$\begin{array}{l}\text { Sood.V } \\
2018 \text { [5] }\end{array}$} & $\begin{array}{l}\text { NAFLD } \\
\text { children }\end{array}$ & India & & & $\begin{array}{l}\text { case control } \\
\text { study }\end{array}$ & & 69 & 22 & 23 & 24 & 71 & 67 & no & 0.005 \\
\hline & NON-NAFLD & & & & & & 30 & 21 & 8 & 1 & 10 & 50 & yes & 0.82 \\
\hline \multirow[t]{2}{*}{$\begin{array}{l}\text { Stasinou.E } \\
2018[6]\end{array}$} & $\begin{array}{l}\text { NAFLD } \\
\text { children }\end{array}$ & Greece & & & $\begin{array}{l}\text { case control } \\
\text { study }\end{array}$ & RFLP & 58 & 8 & 10 & 40 & 90 & 26 & no & 0.0001 \\
\hline & NON-NAFLD & & & & & & 91 & 66 & 22 & 3 & 28 & 154 & yes & 0.49 \\
\hline \multirow[t]{2}{*}{$\begin{array}{l}\text { Hudert.C } \\
2018 \text { [7] }\end{array}$} & $\begin{array}{l}\text { NAFLD } \\
\text { children }\end{array}$ & German & $54 / 16$ & $35.9 \pm 14.5$ & $\begin{array}{l}\text { case control } \\
\text { study }\end{array}$ & TaqMan & 70 & 20 & 31 & 19 & 69 & 71 & yes & 0.339 \\
\hline & NON-NAFLD & & $123 / 77$ & & & & 200 & 118 & 71 & 11 & 93 & 307 & yes & 0.94 \\
\hline \multirow[t]{2}{*}{$\begin{array}{l}\text { Lin.Y-C } \\
2014 \text { [8] }\end{array}$} & $\begin{array}{l}\text { NAFLD } \\
\text { children }\end{array}$ & China & $555 / 242$ & $27.0 \pm 4.1$ & $\begin{array}{l}\text { case control } \\
\text { study }\end{array}$ & TaqMan & 191 & 58 & 95 & 38 & 171 & 211 & yes & 0.93 \\
\hline & NON-NAFLD & & $115 / 47$ & $26.75 \pm 3.85$ & & & 606 & 238 & 293 & 75 & 443 & 769 & yes & 0.29 \\
\hline \multirow[t]{2}{*}{$\begin{array}{l}\text { Shang.X-R } \\
2015 \text { [9] }\end{array}$} & $\begin{array}{l}\text { NAFLD } \\
\text { children }\end{array}$ & China & $459 / 406$ & $20.72 \pm 3.61$ & $\begin{array}{l}\text { case control } \\
\text { study }\end{array}$ & Mass ARRAY & 162 & 60 & 74 & 28 & 130 & 194 & yes & 0.53 \\
\hline & NON-NAFLD & & & $28.8 \pm 2.8$ & & & 865 & 338 & 418 & 109 & 636 & 1094 & yes & 0.24 \\
\hline \multirow{2}{*}{$\begin{array}{l}\text { Bugianesi.E } \\
2017 \text { [10] }\end{array}$} & $\mathrm{NASH}$ & Italy & & $28.2 \pm 3.5$ & case control & TaqMan & 219 & 74 & 101 & 44 & 189 & 249 & yes & 0.37 \\
\hline & NAFL & & $41 / 30$ & $95 \pm 6$ & St & & 69 & 36 & 30 & 3 & 36 & 102 & yes & 0.29 \\
\hline \multirow{2}{*}{$\begin{array}{l}\text { Nobili.V } \\
2014 \text { [11] }\end{array}$} & $\mathrm{NASH}$ & Italy & $51 / 30$ & $95 \pm 6$ & case control & TaqMan & 71 & 48 & 23 & & & & & \\
\hline & NAFL & & $93 / 56$ & & & & 81 & 80 & 1 & & & & & \\
\hline \multirow{2}{*}{$\begin{array}{l}\text { Valenti.L } \\
2010 \text { [12] }\end{array}$} & $\mathrm{NASH}$ & Italy & & & case control & TaqMan & 69 & 1 & 44 & 23 & 90 & 46 & no & 0.0002 \\
\hline & NAFL & & & $28.2 \pm 3.6$ & & & 81 & 64 & 17 & 0 & 17 & 145 & yes & 0.29 \\
\hline \multirow{2}{*}{$\begin{array}{l}\text { Mosca.A } \\
2018 \text { [13] }\end{array}$} & $\mathrm{NASH}$ & Italy & & $27.8 \pm 6$ & case control & TaqMan & 25 & 5 & 13 & 7 & 27 & 23 & yes & 0.82 \\
\hline & NAFL & & & & stl & & 9 & 9 & 0 & 0 & 0 & 18 & & \\
\hline
\end{tabular}


Table 2 Meta-analysis of the association of PNPLA3 rs738409 G/C gene polymorphism and childhood NAFLD susceptibility

\begin{tabular}{|c|c|c|c|c|c|c|c|c|}
\hline \multirow[t]{2}{*}{ Genetic model } & \multicolumn{3}{|l|}{ Relevance test } & \multicolumn{3}{|c|}{ Heterogeneity test } & \multicolumn{2}{|c|}{ Publication } \\
\hline & $\mathrm{OR}(95 \% \mathrm{Cl})$ & Z & $\overline{P_{\text {value }}}$ & $P^{2}$ & $Q$ & $P_{\text {hel }}$ & $P_{\text {egger }}$ & $\mathrm{t}$ \\
\hline dominant gene model & $3.157(1.446-6.892)$ & 2.89 & 0.004 & 90.9 & 43.75 & 0.000 & 0.060 & 2.95 \\
\hline Allelic model & $3.343(1.524-7.334)$ & 3.01 & 0.003 & 95.7 & 93.77 & 0.000 & 0.081 & 2.59 \\
\hline recessive model & $5.692(1.941-16.689)$ & 3.17 & 0.002 & 90.7 & 42.91 & 0.000 & 0.076 & 2.67 \\
\hline super-dominant model & $2.756(1.729-4.392)$ & 4.26 & 0.000 & 80.9 & 20.93 & 0.000 & 0.038 & -3.56 \\
\hline
\end{tabular}

\section{Results}

\section{Characteristics of the included studies}

The flow diagram of study selection was presented in Fig. 1.According to the set search formula, 267 articles that meet the requirements were initially retrieved, and 123 duplicate articles were removed. 82 unrelated documents were excluded after reading the title and abstract.Then 53 articles were excluded after reading the full text leaving 9 articles that were included in the final analysis. 5 literatures described the association between PNPLA3 rs738409 G/C gene polymorphism and susceptibility to childhood NAFLD disease. There were 550 children with NAFLD and 1792 non-NAFLD controls.4 articles described the association between PNPLA3 rs738409 G/C gene polymorphism and the severity of NAFLD in children. There were 383 children with NASH as case group and 240 children with NAFL control as control group contained in this meta analysis.Genotyping data and basic characteristics for all studies are summarized in Table 1.

\section{Meta-analysis results}

The results of association between PNPLA3 rs738409 G/C gene polymorphism and susceptibility to NAFLD in children were presented in Table 2. We found that the PNPLA3 rs738409 G/C gene polymorphism was associated NAFLD in children under four genetic models.(For $\mathrm{GG}+\mathrm{GC}$ vs $\mathrm{CC}$ $\mathrm{OR}=3.157,95 \% \mathrm{CI}=1.446-6.892, P=0.004$; Fig. 2 .For $\mathrm{G}$ vs

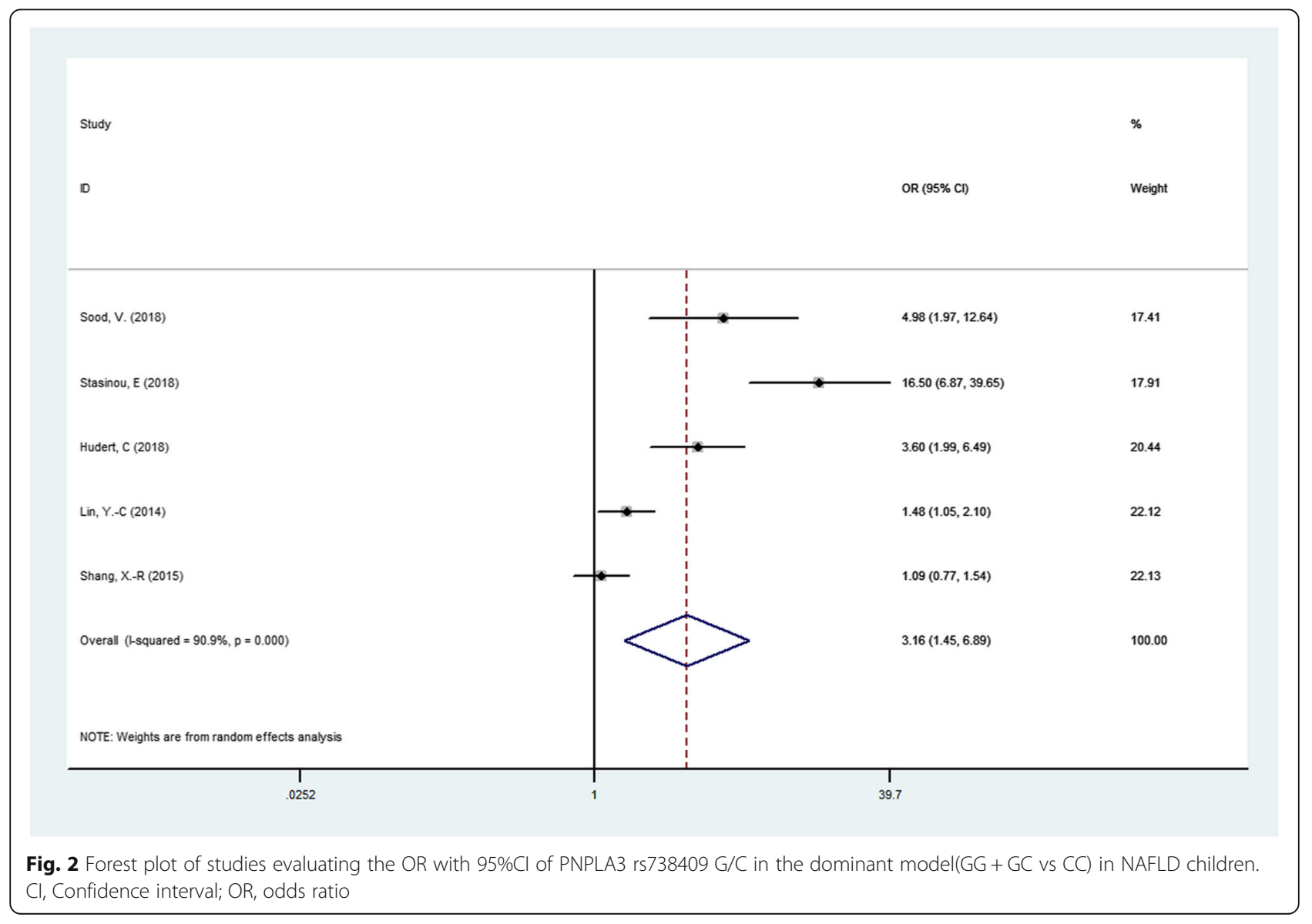




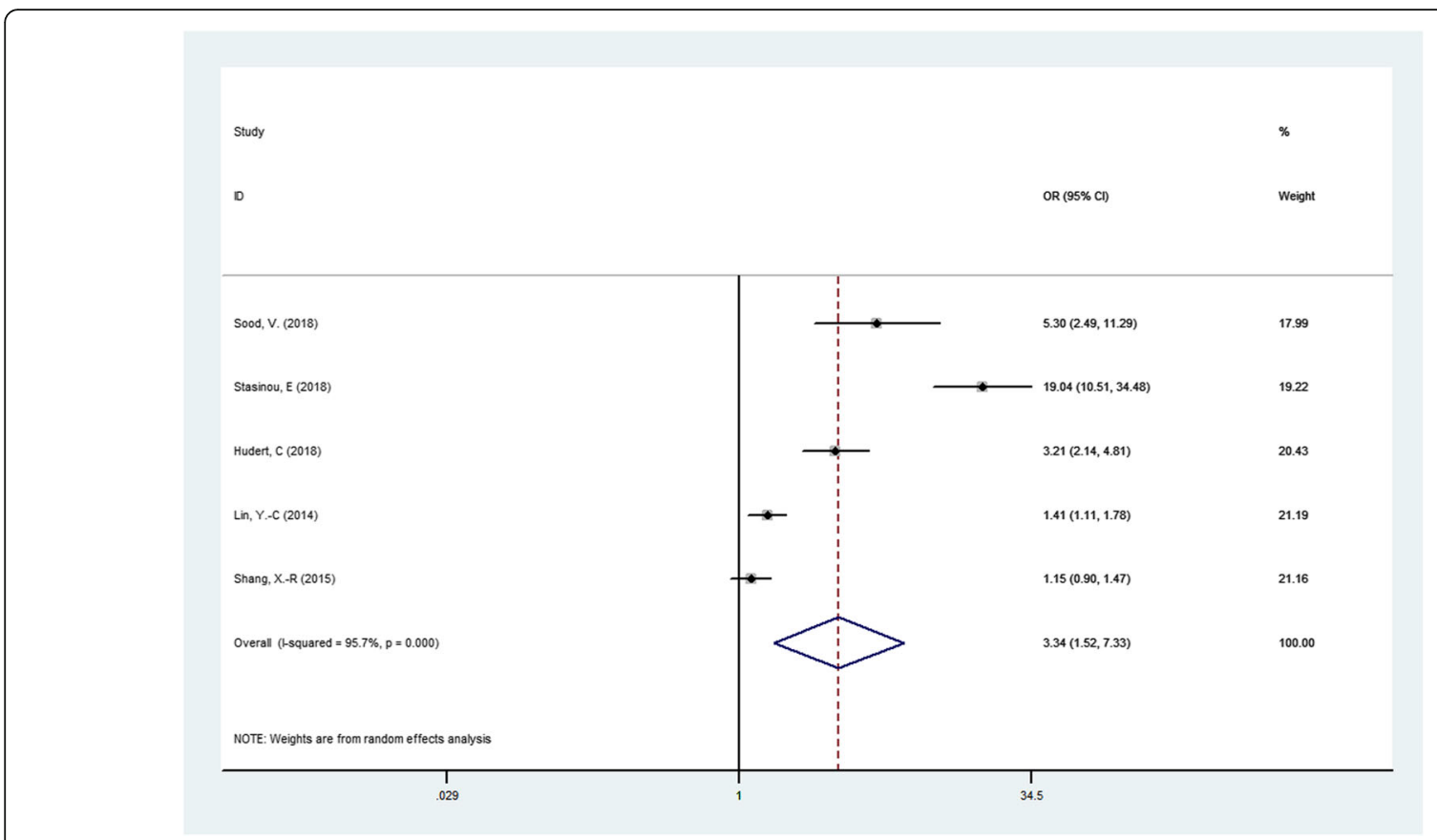

Fig. 3 Forest plot of studies evaluating the OR with $95 \% \mathrm{Cl}$ of PNPLA3 rs738409 G/C in the allele model (G vs C) in NAFLD children. Cl, Confidence interval; OR, odds ratio

OR $(95 \% \mathrm{Cl})$

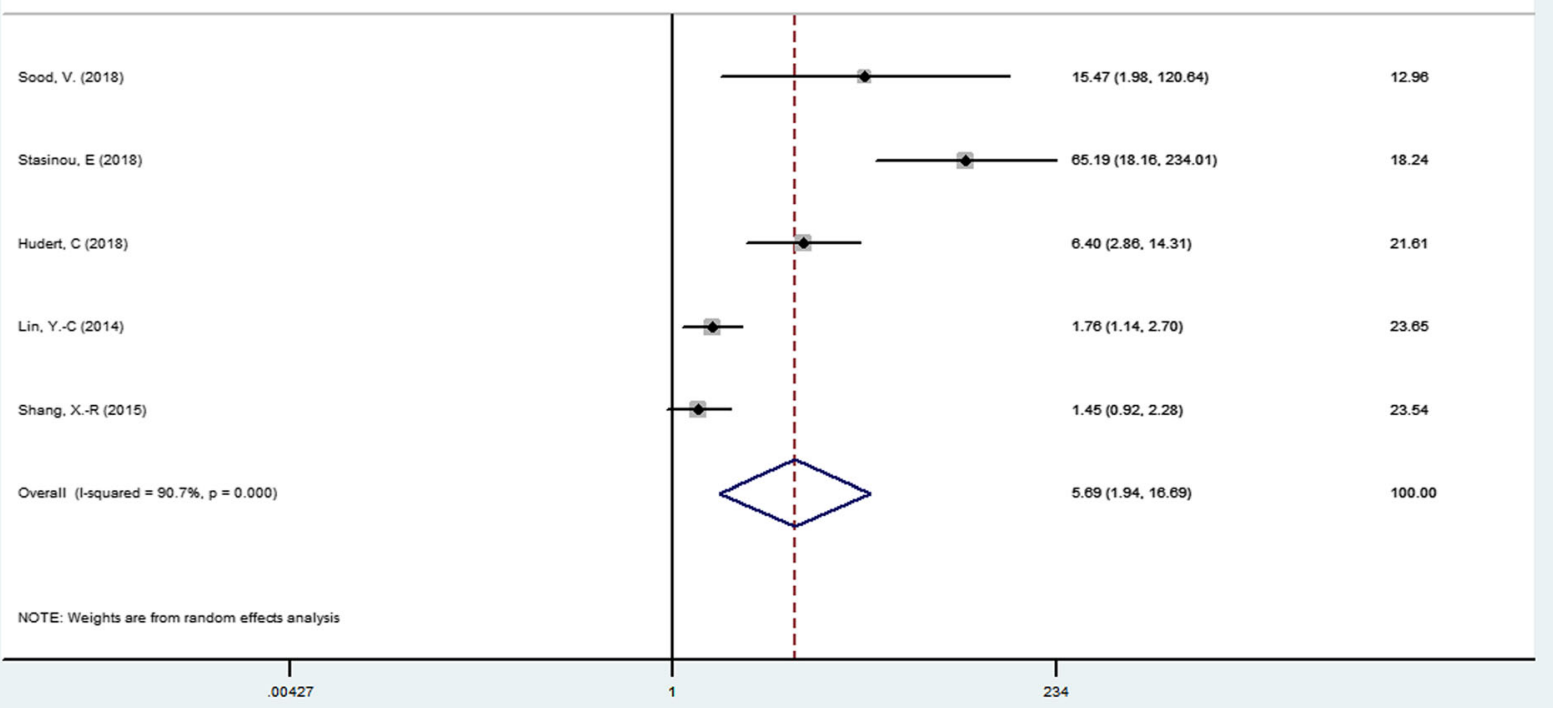

Fig. 4 Forest plot of studies evaluating the OR with $95 \% \mathrm{Cl}$ of PNPLA3 rs738409 G/C in the recessive gene model (GG vs CG + CC) in NAFLD children. $\mathrm{Cl}$, Confidence interval; OR, odds ratio 


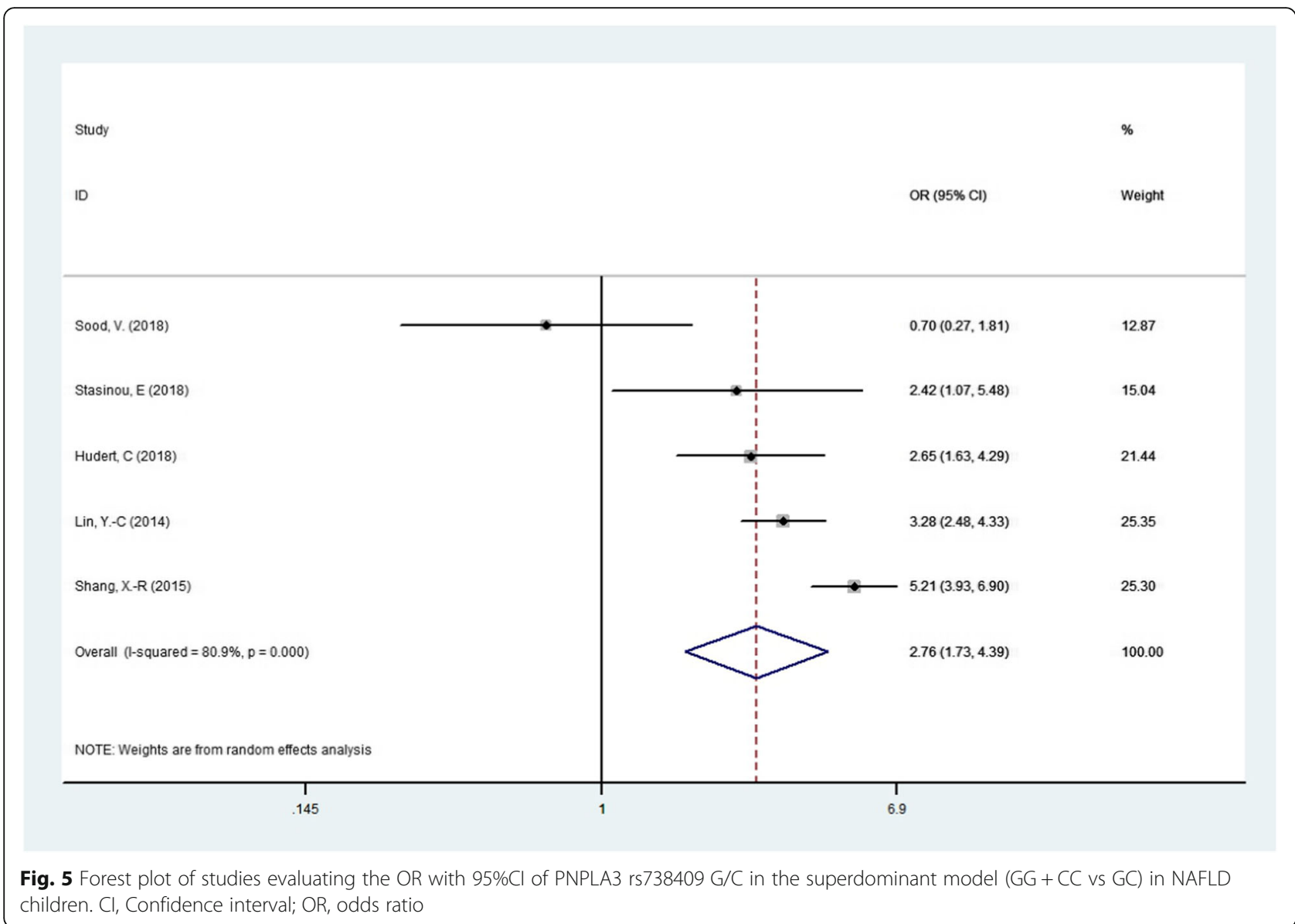

C OR $=3.343,95 \% \mathrm{CI}=1.524-7.334, P=0.003$; Fig. 3.For $\mathrm{GG}$ vs $\mathrm{GC}+\mathrm{CC} \mathrm{OR}=5.692,95 \% \mathrm{CI}=1.941-16.689, P=$ 0.002; Fig. 4.For $\mathrm{GG}+\mathrm{CC}$ vs $\mathrm{GC} \mathrm{OR}=2.756,95 \% \mathrm{CI}=$ 1.729-4.392, $P=0.000$;Fig. 5, respectively),suggesting $G$ allele was a risk factor for NAFLD risk in children.

The result of association between PNPLA3 rs738409 G/C gene polymorphism and susceptibility to NAFLD in children were presented in Table 3.The result showed that the risk of NASH in NAFLD patients with GG genotype was higher than that in $\mathrm{GC}+\mathrm{CC}$ genotypes. (GG vs $\mathrm{GC}+\mathrm{CC} \mathrm{OR}=14.473,95 \% \mathrm{CI}=5.985-34.997$, $P=0.000$; Fig. 6).

\section{Sensitivity analysis and publication bias}

To confirm the stability of above results, sensitivity analysis was performed by omitting one study sequentially to examine its effect on the overall results under all genetic models.The result did not alter after deleting each study, indicating the stability of the results of this meta-analysis. (Supplementary Figures 1, 2, 3, 4, 5).Publication bias of the recruited studies was evaluated using Egger regression analysis and funnel chart, the Egger regression analysis and funnel chart suggested that no evidence of publication bias in this meta-analysis.(Supplementary Figs. 6, 7, 8,9,10, $11,12,13,14,15)$.

\section{Discussion}

The phospholipase domain protein 3(PNPLA3) was originally cloned from the cDNA library of $3 \mathrm{~T} 3$ preadipocytes into mature adipocytes, hence named adiponectin [14]. It is 10 times more expressed in the liver than in adipose tissue [15]. Non-synonymous genetic variation (rs738409) in the human patatin-like phospholipase domain-containing 3 gene (PNPLA3) that substitutes methionine for isoleucine (I148M) at amino acid position 148 in exon 3 was found to be associated with

Table 3 Meta-analysis of the association of PNPLA3 rs738409 G/C gene polymorphism and childhood NASH susceptibility

\begin{tabular}{|c|c|c|c|c|c|c|c|c|}
\hline \multirow[t]{2}{*}{ Genetic model } & \multicolumn{3}{|l|}{ Relevance test } & \multicolumn{3}{|c|}{ Heterogeneity test } & \multicolumn{2}{|c|}{ Publication } \\
\hline & $\mathrm{OR}(95 \% \mathrm{Cl})$ & Z & $\overline{P_{\text {value }}}$ & $\mathrm{R}^{2}$ & Q & $P_{\text {hel }}$ & $P_{\text {egger }}$ & $\mathrm{t}$ \\
\hline recessive model & $14.473(5.985-34.997)$ & 5.93 & 0.000 & 40.0 & 5.00 & 0.172 & 0.602 & 0.61 \\
\hline
\end{tabular}




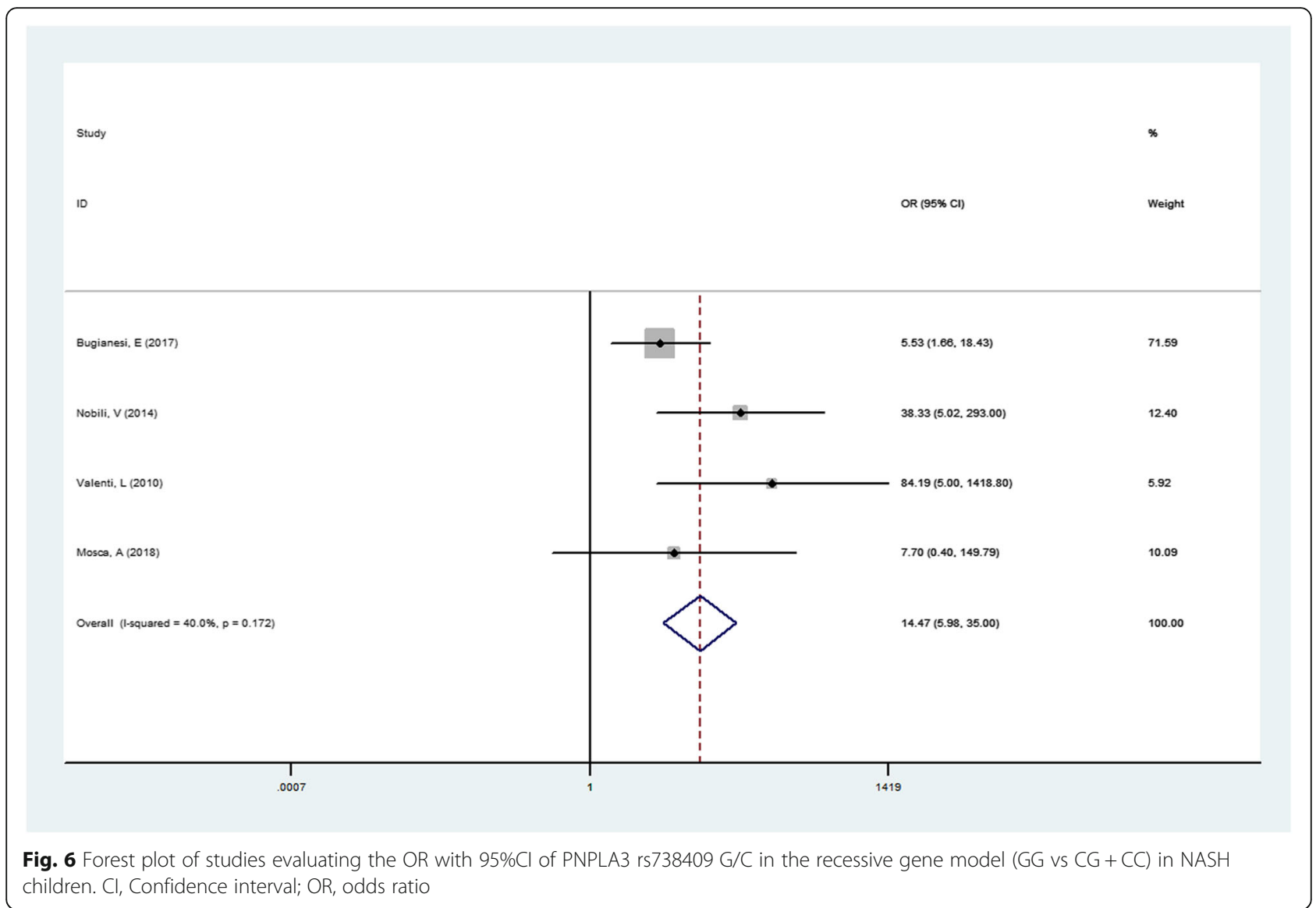

remodeling of liver triglycerides [16]. Hepatocytes expressing PNPLA3-I148M have more long-chain polyunsaturated fatty acids (PUFA) [17]. Mitsche et al. reported that hepatocytes expressing PNPLA3-I148M could transfer PUFA from triglyceride to phospholipid [18]. Phospholipid remodeling is associated with NAFLD susceptibility.

Although the research on the relationship between PNPLA3 gene polymorphism and NAFLD in children has attracted the attention of many researchers, the results vary from study to study. However, these studies were small sample sizes and had low statistical power which may lead to contradictory results. Hence, we performed this meta-analysis by combining the independent studies and estimating the overall effect to overcome the individual limitation and to draw more convinced conclusions.

In this study, by developing a retrieval strategy, literature quality evaluation according to the requirements of the Oxford Critical Appraisal Skill Program (Oxford CASP, 2004) [19], 9 literatures meeting the requirements were included for data extraction. We finally consolidated a total of 5 eligible studies to seek the relationship between PNPLA3 738,409 locus gene polymorphism and NAFLD susceptibility in children. The random effect model was used to conduct combined analysis of the data. Allele model, dominant gene model, recessive gene model and superdominant gene model of PNPLA3 738, 409 locus were analyzed in this study, and the results showed that PNPLA3 738,409 locus gene polymorphism was significantly associated with NAFLD susceptibility in children. 4 literatures studied the relationship between PNPLA3 738,409 locus gene polymorphism and NAFLD severity in children. The fixed effect model was used to conduct combined analysis of the data. Due to data limitations, the recessive gene model of PNPLA3 738,409 locus was analyzed, and the results showed that PNPL A3 738,409 locus gene polymorphism was significantly associated with NASH in children.

At the same time, there are still some limitations in this article. First, due to the lack of a unified document quality evaluation standard, the included articles are subjectively selected and evaluated, which may affect the stability of the meta-analysis results. Second, since metaanalysis itself is a retrospective study, there is a degree of bias. Due to these limitations, we still need to expand the sample size to further and systematically evaluate case-control studies. In addition, this meta-analysis only involved single-factor studies, and did not include the interaction of PNPLA3 gene polymorphism with obesity 
[20] and breastfeeding [21] for hours, and the interaction of the above factors may affect the susceptibility of NAFLD in children.

\section{Conclusion}

In summary, the polymorphism of PNPLA3 738,409 locus gene polymorphism is not only related to the susceptibility of NAFLD in children, but also related to its severity. Because NAFLD in children has no specific clinical manifestations, and ultrasound is not sensitive to the diagnosis of NASH, further studies can be conducted to evaluate whether PNPLA3 738,409 G/C gene polymorphism can be screened for early diagnosis of childhood NAFLD and early evaluation of NAFLD severity.

\section{Supplementary information}

Supplementary information accompanies this paper at https://doi.org/10. 1186/s12881-020-01098-8.

Additional file 1: Supplementary Fig. 1. Sensitivity analysis of the relationship between PNPLA3 rs738409 G/C and NADLD in children in the dominant model(GG + GC vs CC). Supplementary Fig. 2. Sensitivity analysis of the relationship between PNPLA3 rs738409 G/C and NAFLD in children in the allele model ( $G$ vs C). Supplementary Fig. 3. Sensitivity analysis of the relationship between PNPLA3 rs738409 G/C and NAFLD in children in the recessive gene model (GG vs CG + CC). Supplementary Fig. 4. Sensitivity analysis of the relationship between PNPLA3 rs738409 G/C and NAFLD in children in the superdominant model (GG + CC vs CC). Supplementary Fig. 5. Sensitivity analysis of the relationship between PNPLA3 rs738409 G/C and NASH in children in the recessive gene model (GG vs CG + CC). Supplementary Fig. 6. Egger's funnel plot of the relationship between PNPLA3 rs738409 G/C and NADLD in children in the dominant model(GG + GC vs CC). Supplementary Fig. 7. Funnel plot of the relationship between PNPLA3 rs738409 G/C and NADL $D$ in children in the dominant model(GG + GC vs CC). Supplementary Fig. 8. Egger's funnel plot of the relationship between PNPLA3 rs738409 G/C and NAFLD in children in the allele model (G vs C). Supplementary Fig. 9. Funnel plot of the relationship between PNPLA3 rs738409 G/C and NAFLD in children in the allele model (G vs C). Supplementary Fig. 10. Egger's funnel plot of the relationship between PNPLA3 rs738409 G/C and NAFLD in children in the recessive gene model (GG vs CG + CC). Supplementary Fig. 11. Funnel plot of the relationship between PNPLA3 rs738409 G/C and NAFLD in children in the recessive gene model (GG vs CG + CC). Supplementary Fig. 12. Egger's funnel plot of the relationship between PNPLA3 rs $738409 \mathrm{G} / \mathrm{C}$ and NAFLD in children in the superdominant model (GG + CC vs CC). Supplementary Fig. 13. Funnel plot of the relationship between PNPLA3 rs738409 G/C and NAFLD in children in the superdominant model (GG + CC vs CC). Supplementary Fig. 14. Egger's funnel plot of the relationship between PNPLA3 rs738409 G/C and NASH in children in the recessive gene model (GG vs CG + CC). Supplementary Fig. 15. Funnel plot of the relationship between PNPLA3 rs738409 G/C and NASH in children in the recessive gene model ( $G G$ vs $C G+C C$ )

\section{Abbreviations}

NAFLD: Nonalcoholic fatty liver disease; PNPLA3: Patatin-like phospholipase domain containing 3; NAFL: Nonalcoholic fatty liver; NASH: Nonalcoholic steatohepatitis; BMI: Body mass index; HWE: Hardy-Weinberg equilibrium

\section{Acknowledgements}

Not applicable.

\section{Authors' contributions}

ST and JZ contributed equally to this work;ST designed and wrote the manuscript; JZ participated in the design of the study and the revision of the
manuscript;TTM searched the literature and helped to draft the manuscript; HQG and XHW take advantage of the stata software to analyze the data;WYZ,YLL and SL selected and interpreted the data;ZPF,LXM, WL,YRL and $\mathrm{LXQ}$ revised the manuscript; HBY conceived the study, $Y H B$ was corresponding author, every author read and approved the final manuscript.

Funding

Not applicable.

Availability of data and materials

All data generated or analyzed during this study are included in this published article.

Ethics approval and consent to participate

Not applicable.

Consent for publication

Not applicable.

\section{Competing interests}

The authors declare that they have no competing interests.

Received: 25 July 2019 Accepted: 30 July 2020

Published online: 18 August 2020

\section{References}

1. Mazo DF, Malta FM, Stefano JT, et al. Validation of PNPLA3 polymorphisms as risk factor for NAFLD and liver fibrosis in an admixed population. Ann Hepatol. 2019;18(3):466-71.

2. Hotta $\mathrm{K}$, Yoneda M, Hyogo $\mathrm{H}$, et al. Association of the rs738409 polymorphism in PNPLA3 with liver damage and the development of nonalcoholic fatty liver disease. BMC Med Genet. 2010;11:172.

3. Clemente MG, Mandato C, Poeta M, et al. Pediatric non-alcoholic fatty liver disease: recent solutions, unresolved issues, and future research directions. World J Gastroenterol. 2016:22:8078-93.

4. Romeo S, Kozlitina J, Xing C, et al. Genetic variation in PNPLA3 confers susceptibility to nonalcoholic fatty liver disease. Nat Genet. 2008:40:1461-5.

5. Sood V, Khanna R, Rawat D, et al. Predictive risk factors and transient elastography in pediatric non alcoholic fatty liver disease in Indian population. J Pediatr Gastr Nutr. 2018;66:84

6. Stasinou E, Argyraki M, Lambropoulos A, et al. Association of the variants rs738409 and rs2896019 in the palatin-like phospholipase 3 gene (PNPLA3) in Greek children and adolescents with fatty liver disease. J Pediatr Gastr Nutr. 2018:66:86.

7. Hudert CA, Selinski S, Rudolph B, et al. Genetic determinants of steatosis and fibrosis progression in pediatric non-alcoholic fatty liver disease. BMC Pediatr. 2013;13:40.

8. Lin Y, Chang P, Chang M, et al. Genetic variants in GCKR and PNPLA3 confer susceptibility to nonalcoholic fatty liver disease in obese individuals. Am J Clin Nutr. 2014:99:869-74.

9. Shang X, Song J, Liu F, et al. GWAS-identified common variants with nonalcoholic fatty liver disease in Chinese children. J Pediatr Gastr Nutr. 2015;60:669-74.

10. Bugianesi E, Bizzarri C, Rosso C, et al. Low Birthweight increases the likelihood of severe Steatosis in pediatric non-alcoholic fatty liver disease. Am J Gastroenterol. 2017;112:1277-86.

11. Nobili $\mathrm{V}$, Donati $\mathrm{B}$, Panera $\mathrm{N}$, et al. A 4-polymorphism risk score predicts steatohepatitis in children with nonalcoholic fatty liver disease. J Pediatr Gastroenterol Nutr. 2014;58:632-6.

12. Valenti L, Alisi A, Galmozzi E, et al. I148M patatin-like phospholipase domain-containing 3 gene variant and severity of pediatric nonalcoholic fatty liver disease. Hepatology. 2010;52:1274-80.

13. Mosca A, Fintini D, Scorletti $E$, et al. Relationship between non-alcoholic steatohepatitis, PNPLA3 1148M genotype and bone mineral density in adolescents. Liver Int. 2018;38:2301-8.

14. Basu RS. PNPLA3-I148M: a problem of plenty in non-alcoholic fatty liver disease. Adipocyte. 2019;8:201-8.

15. Wilson PA, Gardner SD, Lambie NM, et al. Characterization of the human patatin-like phospholipase family. J Lipid Res. 2006;47:1940-9. 
16. Baclig MO, Lozano-Kuhne JP, Mapua CA, et al. Genetic variation I148M in patatin-like phospholipase 3 gene and risk of non-alcoholic fatty liver disease among Filipinos. Int J Clin Exp Med. 2014;7:2129-36.

17. Ruhanen H, Perttila J, Holtta-Vuori M, et al. PNPLA3 mediates hepatocyte triacylglycerol remodeling. J Lipid Res. 2014;55:739-46.

18. Mitsche MA, Hobbs HH, Cohen JC. Patatin-like phospholipase domaincontaining protein 3 promotes transfer of essential fatty acids from triglycerides to phospholipids in hepatic lipid droplets. J Biol Chem. 2018; 293:9232.

19. Serou N, Sahota L, Husband AK, et al. Systematic review of psychological, emotional and behavioural impacts of surgical incidents on operating theatre staff. BJS Open. 2017;1:106-13.

20. Kleiner DE, Brunt EM. Nonalcoholic fatty liver disease: pathologic patterns and biopsy evaluation in clinical research. Semin Liver Dis. 2012;32:3-13.

21. Ayonrinde OT, Oddy WH, Adams LA, et al. Infant nutrition and maternal obesity influence the risk of non-alcoholic fatty liver disease in adolescents. J Hepatol. 2017;67:568-76.

\section{Publisher's Note}

Springer Nature remains neutral with regard to jurisdictional claims in published maps and institutional affiliations.

Ready to submit your research? Choose BMC and benefit from:

- fast, convenient online submission

- thorough peer review by experienced researchers in your field

- rapid publication on acceptance

- support for research data, including large and complex data types

- gold Open Access which fosters wider collaboration and increased citations

- maximum visibility for your research: over $100 \mathrm{M}$ website views per year

At BMC, research is always in progress.

Learn more biomedcentral.com/submissions 